\title{
MicroRNA-26b inhibits cell proliferation and crossuak cytokine secretion in human RASF cells via the Wnt/GSK-3 $\beta / \beta$-catenin pathway
}

\author{
Jiling Sun ${ }^{1}$, Peng Yan ${ }^{2}$, Yuanzheng Chen ${ }^{3}$, Yang Chen ${ }^{4}$, Jianxun Yang ${ }^{4 *}$, Guangyue X ${ }^{5}$, Haijun Mao ${ }^{5}$ and Yong Qiu ${ }^{5}$
}

\begin{abstract}
Background: Rheumatoid arthritis (RA) is a chronic systemic auto- immune disease characterized by joint synovitis. Recent evidence suggests that rheumatoid arthritis synovial fibroblasts (RASFs) promote joint destruction. In this study, we investigated the role of microRNA-26b (miR-26b) in cell proliferation and inflammatory cytokine secretion using patient-derived Rheumatoid arthritis fibroblast-like synoviocyte (RAFLS) to understand pathways influencing rheumatoid arthritis.
\end{abstract}

Methods: RAFLS were cultured in vitro and transfected with miR-26b mimics (experimental group) and negative

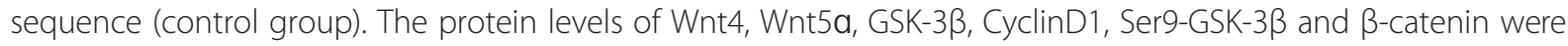
detected by western blot analysis. Tumor Necrosis Factor-a (TNF-a), IL-1 13 , and IL-6 levels were quantified by Enzymelinked Immunosorbent Assay (ELISA). RAFLS proliferation and apoptosis were measured by 3-[4, 5-dimethylthiazol-2-yl]-2, 5-diphenyl tetrazolium bromide (MTT) assay and flow cytometry, respectively.

Results: GSK-3 $\beta$ and CyclinD1 expression levels were lower in miR-26b mimic group compared to Mock group and negative control (NC) group. Conversely, GSK-3 3 and CyclinD1 expression levels were markedly higher in the miR-26b inhibitor group compared to Mock and NC group $(P<0.05)$. Transfection of miR-26b mimics significantly increased the, levels of Ser9-GSK-3 $\beta$ and $\beta$-catenin in comparison to Mock and NC groups, while transfection of miR-26b inhibitors showed the opposite effect. In miR-26b mimic group, TNF-a, IL- $1 \beta$ and IL-6 levels were lower than the Mock and NC groups, while in miR-26b inhibitor group, these cytokine levels were higher than the Mock and NC groups $(P<0.05)$. Transfection of miR-26b mimics significantly reduced the cell proliferation of RAFLS, compared to the Mock and NC groups, and miR-26b inhibitors increased the proliferative capacity of RAFLS compared to Mock and NC groups $(P<0.05)$. The miR-26b mimic group exhibited higher RAFLS apoptosis rate compared to Mock and NC group and miR-26b inhibitor group showed significantly lower RAFLS apoptosis rate compared to Mock and NC groups $(P<0.05)$.

Conclusions: MiR-26b regulates $\beta$-catenin and CyclinD1 levels by inhibiting GSK-3 $\beta$ expression, which in-turn alters the

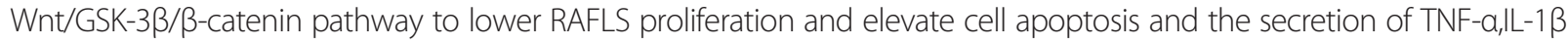
and IL-6 cytokines. Therefore, our results show that miR-26B plays a central role in inhibiting the inflammation associated with rheumatoid arthritis.

Virtual Slides: The virtual slide(s) for this article can be found here: http://www.diagnosticpathology.diagnomx.eu/vs/ 9063056861547150

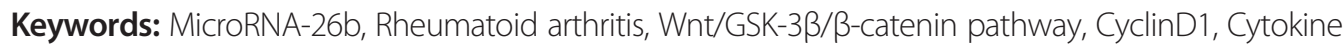

\footnotetext{
*Correspondence: yangjianxun0515@163.com; qiuyong0623@163.com

${ }^{4}$ Department of Orthopedics, Linyi People's Hospital, North of Yimeng Road, Lanshan District, Linyi 276000, P. R. China

Full list of author information is available at the end of the article
} 


\section{Background}

Rheumatoid arthritis (RA) is a chronic systemic autoimmune disease characterized by joint synovitis $[1,2]$. The clinical manifestations of RA includes joint swelling and pain caused by synovitis, cartilage destruction, joint space narrowing, joint stiffness, deformity and dysfunction, which are directly related to primary chronic low-grade inflammation [3, 4]. RA affects $0.5-1 \%$ of adults in developed countries and approximately $5-50$ per 100,000 population in developing countries each year [5]. RA onset is rare under the age of 15, but its incidence shows a steady increase with age until 80, with women 3-5 times more susceptible than men [6]. The exact cause of RA is still unknown, but genetic factors, such as human leukocyte antigen-DR4 (HLA-DR4) and other non-HLA genes including protein tyrosine phosphatase, non-receptor type 22 (PTPN22) and peptidyl arginine deiminase, type IV (PADI4), are suspected as major contributing factors $[7,8]$. Non-genetic factors also contribute significantly to RA and include Epstein-Barr virus (EBV) and Human Herpes Virus 6 (HHV-6) infections, hormonal infleunces, smoking, cold temperatures and trauma $[9,10]$. Previous studies show that loss of balance in proliferation and apoptosis of synovial fibroblast (SF) and abnormal secretion of various cytokines play key roles in RA pathogenesis. Multiple signaling pathways are activated during RA development [11, 12]. Synovial tissue from RA patients shows infiltration by macrophages, $\mathrm{T}$ cells, and $\mathrm{B}$ cells, proliferation of cells lining the synovium, and production of inflammatory cytokines such as tumor necrosis factor $\alpha$ (TNF $\alpha)$ and interleukin-1 $\beta$ (IL-1 $\beta)$ [13, 14]. Interestingly, inhibition of these cytokines ameliorates the clinical symptoms RA, strongly supporting the central role of cytokines in RA [15]. Rheumatoid arthritis synovial fibroblast (RASFs) activity promotes joint destruction and increased expression of proinflammatory pathways and secretion of matrixdestructive enzymes is a common feature associated with the disease [16]. Recent evidence suggests that miRNA dysregulation may contribute to RA etiopathogenesis and therefore, a better understanding of pathways regulated by miRNAs might shed light on RA pathogenesis and help identify effective RA treatments [17].

MicroRNAs (miRNAs) are small, non-coding endogenous RNAs of $20 \sim 24$ nucleotides in length and regulate gene expressions at the post-transcriptional level [18]. MiRNAs bind to 3' untranslated regions (3' UTRs) of their target mRNAs and either block translation and/or promote target mRNA degradation [19]. MiRNAs play important roles both in pathological and normal physiological processes such as embryonic development, energy homeostasis, metabolism of sugar and lipid as well as tumorigenesis [20-23]. Several miRNAs modify cell behavior by regulating the nuclear factor- $k B(\mathrm{NF}-\mathrm{kB})$ pathway [18]. For instance, miR-30e, miR-182, and miR-301a promote NF- $\mathrm{kB}$ activity to enhance tumor growth, invasiveness or angiogenesis [24-26]. Joanna Stancz et al. observed dysregulated expression of miRNA miR-155 and miR-146a in synovial tissue, synovial fibroblasts and monocytes of rheumatoid joints [16]. Previous studies showed that the miR-26 family, consisting of miR-26a and $\mathrm{miR}-26 \mathrm{~b}$, is down-regulated in several cancers such as hepatocellular carcinoma (HCC), melanoma, nasopharyngeal carcinoma and breast cancer [27-31]. Although the cellular functions of miR-26b remain elusive, miR-26b inhibits NF- $\kappa B$ pathway in HCC cells by suppressing TAK1 and TAB3 expression, and down-regulation of miR-26b suppressed apoptosis in HCC cells [18]. Thus far, the main role of miR-26b was described in cancers. However, due to the close relationship between cancer and inflammatory pathway, we investigated whether miR-26b influenced cell proliferation and inflammatory cytokine secretion in RASF cells and further sought to identify the underlying mechanisms.

\section{Methods}

\section{Ethics Statement}

The study was approved by the Institutional Review Boards (IRBs) of Linyi People's Hospital. Written informed consent was obtained from each eligible participant and the study was performed in accordance with the Declaration of Helsinki.

\section{Culture of rheumatoid arthritis fibroblast-like synoviocytes (RAFLS)}

Human synovial tissues from the affected joints were collected from patients admitted at the Linyi People's Hospital signed informed consent forms were obtained before the procedure. The diagnosis of RA in these patients was according to American Rheumatism Association 1987 revised criteria for classification of rheumatoid arthritis [32]. Synovial tissues were obtained from RA patients at surgery. They collected tissue samples were minced and digested with $2.5 \mathrm{~g} / \mathrm{L}$ trypsase for $2 \mathrm{~h}$ at $37{ }^{\circ} \mathrm{C}$ and cells were collected after centrifugation and cultured in Dulbecco's minimum essential medium (DMEM) in $5 \% \mathrm{CO}_{2}$ at $37{ }^{\circ} \mathrm{C}$. The cells were cryopreserved between $3^{\text {rd }}-8^{\text {th }}$ passage and cells within these passages were chosen for all experiments.

\section{Cell grouping and transfection}

The experimental set-up consisted of 4 groups: the Mock group, negative control (NC group transfected with miR26b negative control sequence), miR-26b mimics group (transfected with miR-26b mimics) and the miR-26b inhibitor group (transfected with miR-26b inhibitor). RAFLS in logarithmic phase cultured in DMEM with 10 \% FBS were detached to for single cell suspension. They were adjusted to $1 \times 10^{6} \mathrm{cell} / \mathrm{ml}$ concentration and seeded 
into 6-well culture plates. Cell transfections were performed when the seeded cells reached $80 \%$ confluency. Lipofectamine 2000 (Invitrogen Company, USA) was used to transfect the cells. Plasmids $(1 \mu \mathrm{g})$ carrying the respective miR-26b sequences were mixed separately with serum-free medium and $2.5 \mu \mathrm{l}$ lipofectamine 2000 and incubated at room temperature for 15 min under serum-free conditions to form transfection complexes. The RAFLS were washed twice with PBS and the corresponding transfection complexes were added to each well. Complete DMEM media was replaced $6 \mathrm{~h}$ later. The transfection efficiency was verified by fluroscence microscopy at $24 \mathrm{~h}$ and $48 \mathrm{~h}$, and cells at $48 \mathrm{~h}$ posttransfection were used for further analsis.

\section{Real-time quantitative polymerase chain reaction (PCR) technique for measurement of miR-26b expression}

Trizol reagent was used to purify total RNA and $0.05 \mu \mathrm{g}$ of the total RNA was used for first strand cDNA synthesis using SuperscriptII reverse transcriptase. Specific primers for miRNA for real-time quantitative PCR and first strand cDNA synthesis were based on published sequences. Light Cycler PCR and the reagents were lightcycler-faststart DNA master SYBR green were from Roche. Reaction conditions were: magnesium concentration was $3 \mathrm{mmol} / \mathrm{L}$, primer concentrations were $0.25 \mu \mathrm{mol} / \mathrm{L}$; denaturation for $15 \mathrm{~s}$ at $95{ }^{\circ} \mathrm{C}, 60{ }^{\circ} \mathrm{C}$ and then anneal for $30 \mathrm{~s}$, repeated 40 cycles. Solubility curve were protracted at $70{ }^{\circ} \mathrm{C}$ to $95^{\circ} \mathrm{C}$ and PCR products were verified by electrophoresis.

\section{Dual-luciferase enzyme assay system for reporter gene analysis}

The cells were transfected as mentioned above and the transfected cells at $48 \mathrm{~h}$ were washed with $1 \times \mathrm{PBS}$. The cells were treated with lysis buffer and Dual-Luciferase ${ }^{\circ}$ Reporter Assay (Promega) was performed, using luminometer, to measure the activity of luciferase. The firefly luciferase activity values were recorded and compared to the Ranilla luciferase activity to quantify transfection efficiency.

\section{Western blot}

Wnt4, Wnt5 $\alpha$, GSK-3 $\beta$, CyclinD1, Ser9-GSK-3 $\beta$ and $\beta$ catenin protein levels were detected by western blot analysis. RIPA lysis buffer was used to exact proteins and BCA method was used to estimate total protein concentration. The samples were electrophoresed in $10 \%$ SDS-PAGE gels $(100 \mathrm{v}, 100 \mathrm{~min})$. The proteins were transferred to PVDF membranes (Invitrogen company) and blocked with $10 \%$ skimmed milk. Next, corresponding primary antibodies (1: 1000) were used to detected the protein, the membranes were washed with TBST thrice and incubated with horseradish peroxidase (HRP)-labeled secondary antibody for $1 \mathrm{~h}$ and DAB staining was performed after washing the membranes, followed by recording the results using gel imaging system. The quantitative measurement of the proteins was as follows: relative expression of the target protein = grey level of target band $/$ grey level of the same sample reference.

\section{Experimental Study of Enzyme-linked Immunosorbent Assay (ELISA) method}

Tumor Necrosis Factor- $\alpha$ (TNF- $\alpha$ ), IL- $1 \beta$, and IL-6 levels were detected using ELISA kit (BD Company, USA). The cells were centrifuged at $1500 \mathrm{rpm}$ for $5 \mathrm{~min}$ in $4{ }^{\circ} \mathrm{C}$. The samples were resuspended at $1 \times 10^{6}$ cells/ $\mathrm{ml}$ and seeded into 12-well plates. Criss-cross serial dilution analysis was adopted to ensure the cell numbers and concentration of labelled complex. From each well, $100 \mu \mathrm{l}$ cell suspensions were added to ELISA plate, centrifuged at $1500 \mathrm{rpm}$ for $1 \mathrm{~min}$, incubated to allow coating and then the supernatants were removed. To each well, $100 \mu \mathrm{l}$ of antibody solution diluted in PBS was used and incubated for $90 \mathrm{~min}$ at $4{ }^{\circ} \mathrm{C}$. Next, $100 \mu \mathrm{l}$ enzymeantibody complex diluted in PBS was added to each well and incubated for $90 \mathrm{~min}$ at $4{ }^{\circ} \mathrm{C}$ and washed 3 times. A $100 \mu \mathrm{l}$ volume of substrate solution was added to each well and incubated for $1 \mathrm{~h}$ at room temperature and the detection was at $450 \mathrm{~nm}$ to measure the absorbance.

Cell proliferation detected by 3-[4, 5-dimethylthiazol-2-yl]-2, 5-diphenyl tetrazolium bromide (MTT) assay

RAFLS in each group were collected and the cell concentration was adjusted to $1 \times 10^{6} \mathrm{cells} / \mathrm{ml}$, and inoculated into 96 -well culture plate $(100 \mu \mathrm{L} /$ well $)$ for various times. The cells were incubated with $20 \mu \mathrm{L}$ MTT $(5 \mathrm{mg} / \mathrm{ml}$, Sigma Chemicals Co.) for $4 \mathrm{~h}$. Next, $200 \mu \mathrm{l}$ DMSO were added to each well and incubated at room temperature for $10 \mathrm{~min}$ in dark to dissolve the complexes. To plot the MTT curves, absorbance values were used as ordinate and time interval was the abscissa. All samples were in triplicates and the experiment was repeated 3 times.

\section{Cell apoptosis assayed by flow cytometry}

AnnexinV-FITC (Sigma Chemicals Co) was used according to manufacturer's instructions. Briefly, cells from each group were washed 3 times in pre-cooled PBS. A volume of $1 \mu \mathrm{l} 1 \times$ annexin $\mathrm{V}$ was combined with buffer solution, centrifuged to discard the liquid supernatant and $200 \mu \mathrm{L}$ binding buffer added to resuspend the cells. A volume of $10 \mu \mathrm{L}$ annexin V-FITC and $5 \mu \mathrm{l} \mathrm{PI}(5 \mathrm{mg} / \mathrm{L})$ were added, mixed and incubated for $30 \mathrm{~min}$ in dark, followed by flow cytometry (Olympus company) to quantify the apoptosis rate. 


\section{Statistical analysis}

All statistical analyses were performed using SPSS 18.0 software (SPSS, Inc., Chicago, IL, USA). All data were expressed as mean \pm SEM. Differences between groups were measured using independent samples $t$-test. A $P<0.05$ value denoted statistically significant difference.

\section{Results}

Expression of green fluorescent protein (GFP) after RAFLS transfection in each group

Following the transfection of RAFLS with various plasmids as indicated, the GFP marker expressed by the recombinant plasmid was used to determine transfection efficiency by fluorescence microscopy (Fig. 1). After $24 \mathrm{~h}$ of transfection, GFP express was visible and this expression significantly increased after $48 \mathrm{~h}$.

\section{Confirmation of miR-26b expression by real-time quantitative PCR}

Figure 2 shows that the expression level of miR-26b in both Mock group and NC group were $1.05 \pm 0.05$ and $1.04 \pm 0.06$, respectively $(P>0.05)$. The expression level in mimic group was $2.56 \pm 0.15$, which was higher than the Mock group and NC group (all $P<0.05$ ). In miR-26b inhibitor group, miR-26b expression level was $0.23 \pm$ 0.04 , significantly lower than Mock and NC groups (all $P<0.05)$.

\section{Confirmation of target-gene of miR-26b by dual-luciferase reporter gene system}

Using bioinformatics Target Scan software (http:// www.targetscan.org), the potential target-genes of miR$26 \mathrm{~b}$ were analyzed. The 3 '-UTR of GSK-3 $\beta$ was highly conserved between different species and contained the binding site for mir-26b (Fig. 3a). As shown in Fig. 3b, recombinant plasmids containing Wt- miR-26b/GSK-3 $\beta$ and Mut- miR-26b/GSK-3 $\beta$ were constructed and cotransfected with miR-26b mimics. The results of the dual luciferase activity assays indicated that miR-26b mimics did not influence luciferase activity in Mut- miR-

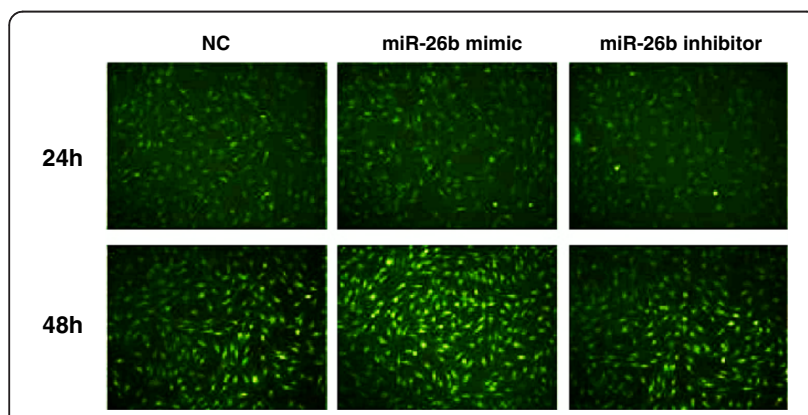

Fig. 1 Expression of green fluorescent protein (GFP) in RAFLS at 24 and $48 \mathrm{~h}$ post-transfection

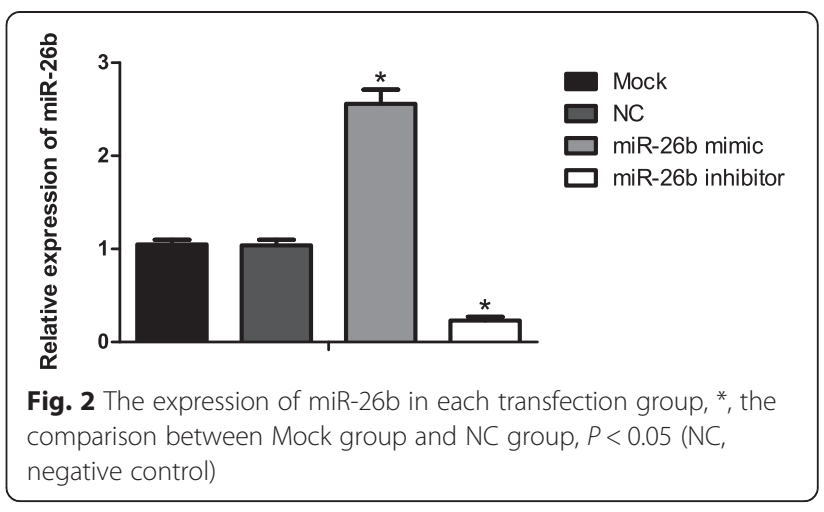

26b/GSK-3 $\beta$, but sharply decrease luciferase activity when the 3 ' -UTR contained Wt- miR-26b/GSK-3 $\beta$ (all $P<0.05$ ).

Expression of nt4, Wnt5a, GSK-3 $\beta$, CyclinD1, phosphorylationSer9-GSK-3 $\beta$ and $\beta$-catenin

As shown in Fig. 4, Wnt4 and Wnt5 expression level in each group showed no significant differences $(P>0.05)$. By contrast, GSK-3 $\beta$ and CyclinD1 expression levels in miR-26b mimic group were lower than the Mock group and NC group (all $P<0.05$ ). Conversely, the expression level of GSK-3 $\beta$ and CyclinD1 in the miR-26b inhibitor group was higher than the Mock and NC group $(P<0.05)$. In the miR-26b mimic group, expression levels of Ser9GSK-3 $\beta$ and $\beta$-catenin were higher than Mock and NC groups (all $P<0.05$ ), while in the miR-26b inhibitor group, their levels were significantly lower (all $P<0.05$ ). The expression of GSK-3 $\beta$, CyclinD1, Ser9-GSK-3 $\beta$ and $\beta$ catenin were not different statistically (all $P>0.05$ ).

\section{TNF- $\alpha$, IL- $1 \beta$ and IL- 6 levels}

TNF- $\alpha$, IL- $1 \beta$ and IL- 6 levels were quantified by ELISA (Fig. 5). TNF- $\alpha$, IL- $1 \beta$ and IL-6 levels showed no statistical differences between the Mock and NC groups (all $P>0.05)$. However, in the miR-26b mimic group, these cytokine levels were significantly lower than the Mock and NC groups (all $P<0.05$ ). On the other hand, in the miR-26b inhibitor group, the cytokines levels were higher than in the Mock and NC groups (all $P<0.05$ ).

\section{Proliferation capacity of RAFLS}

The RAFLS cell proliferation was measured by MTT method, as shown in Fig. 6. We observed no differences in cell proliferation capacity between the Mock group and NC group $(P>0.05)$. In miR-26b mimic group, the RAFLS cell proliferation capacity was significantly lower than the Mock and NC groups (all $P<0.05$ ). In the miR26b inhibitor group, the proliferation capacity of RAFLS was significant higher than Mock and NC groups (all $P<0.05)$. 


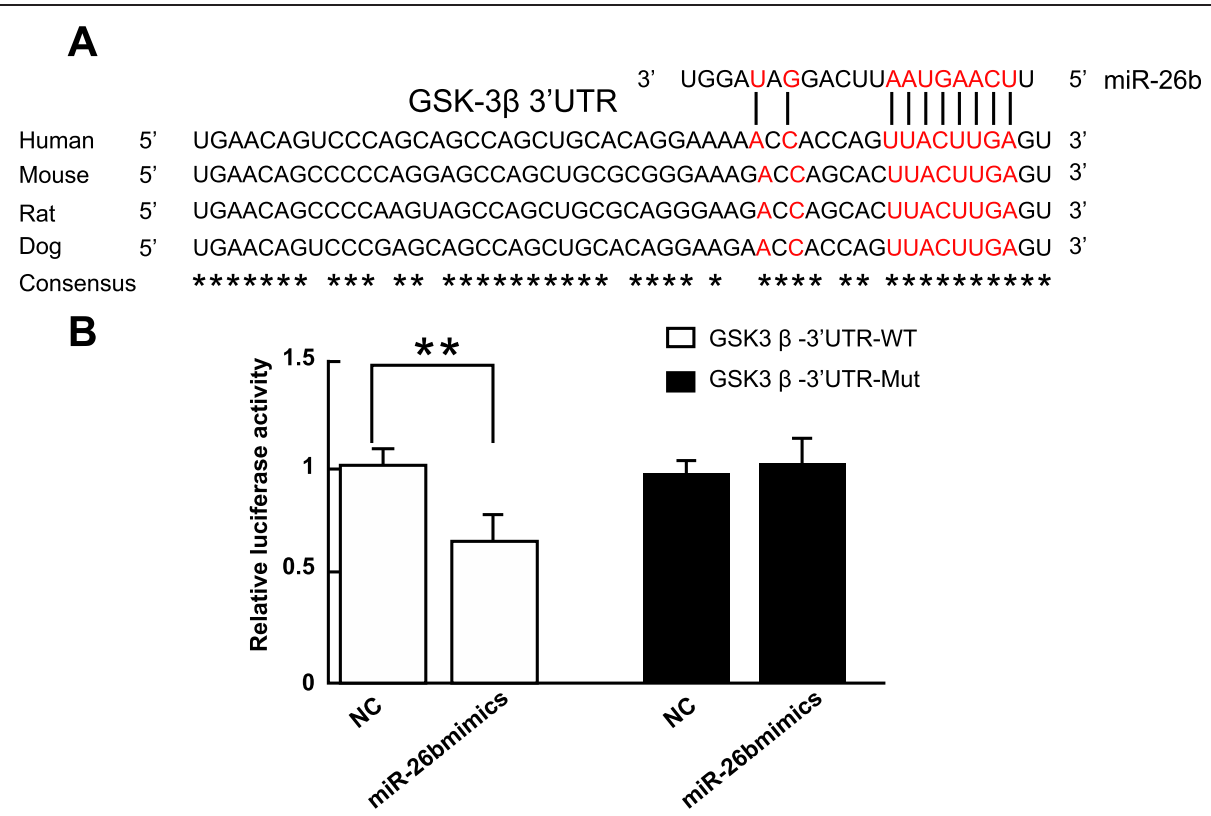

Fig. 3 GSK-3 $\beta$ is the target of miR-26b. a: the comparison between miR-26b and $3^{\prime} U T R$ of GSK-3 $\beta$, the red part is complementary sites (core sequence, also

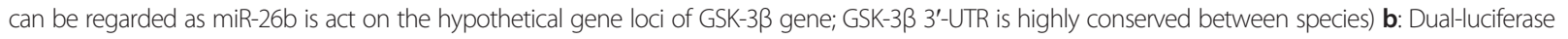
assay for reporter gene analysis; detected in RAFLS cotransfected miR-26b mimics and GSK-3 3 3'-UTR Wt/Mu plasmid; miR-26b inhibited activity of luciferase containing Wt $3^{\prime}-U T R$, ${ }^{*} P<0.05$, while Mut plasmid activity of luciferase showed no change. NC, negative control

\section{Effects of MiR-26b on RAFLS apoptosis}

As shown in Fig. 7, RAFLS apoptosis rates between the Mock and NC groups were not significantly different $(P>0.05)$. However, in the miR-26b mimic group, RAFLS apoptosis was markedly higher than observed in the Mock and NC groups (all $P<0.05$ ). In the miR-26b inhibitor group, RAFLS apoptosis was significant lower than the Mock and NC groups (all $P<0.05$ ).

\section{Results and discussion}

RA is a chronic systemic disease characterized by inflammatory synovitis [33]. RA pathology is influenced by
A

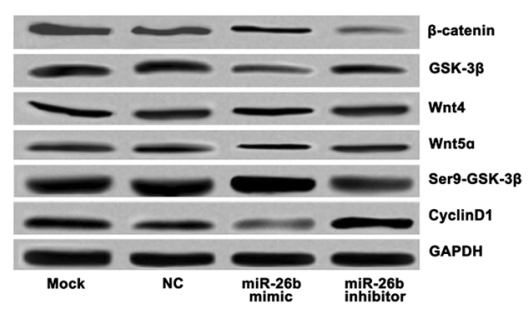

C

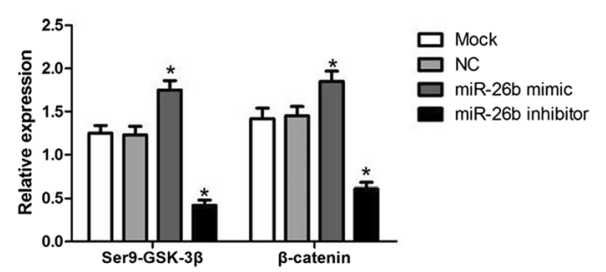

B

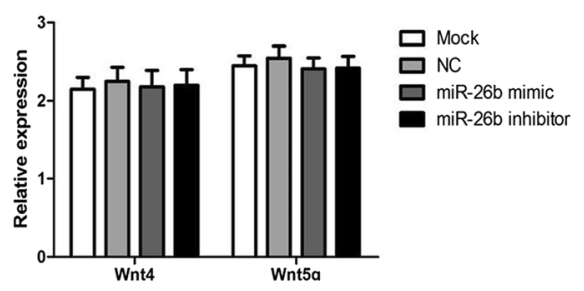

D

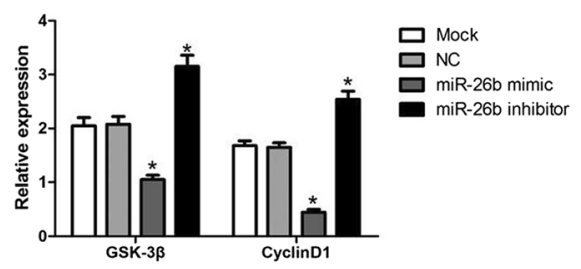

Fig. 4 Expression of Wnt4, Wnt5a, Ser9-GSK-3ß, CyclinD1 and $\beta$-catenin, ${ }^{*}$, the comparison between Mock group and NC group, P<0.05. a, Western blot of Wnt4, Wnt5a, Ser9-GSK-3ß, CyclinD1 and $\beta$-catenin expression; $\mathbf{b}$, relative expression of Wnt4 and Wnt5a in the 4 experimental groups; c, relative expression of Ser9-GSK-3 $\beta$ and $\beta$-catenin in the 4 groups; $\mathbf{d}$ : relative expression of GSK-3 $\beta$ and CyclinD1 in the 4 groups ( 4 groups: Mock, NC, miR-26b mimic and miR-26b inhibitor group). NC, negative control 


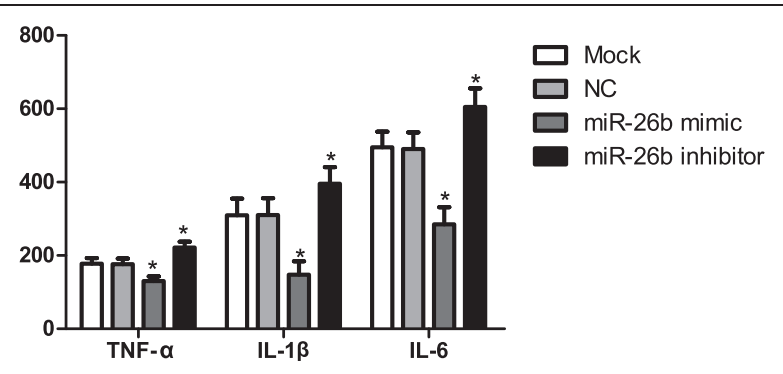

Fig. 5 The ELISA results of TNF- $a, L-1 \beta a n d ~ I L-6$ levels, *, the comparison between Mock group and NC group, $P<0.05$. NC, negative control

several risk factors such as environmental factors, activated cellular pathways, viral infections, genetic factors, hormonal influences and psychological state [34]. RA is associated with significant comorbidities, articular damage, disability and increased mortality [35]. MiRNAs are a new class of small no-coding single-stranded RNAs 13-21 nucleotides in length and function as post-transcriptional regulators of gene expression by complementary binding to target mRNAs [36, 37]. MiRNAs are excellent candidates as molecular biomarkers for diagnosis and prognosis in several human pathological conditions [38, 39]. Shang et al. showed that miRNAs also influence the disease course in severe joint diseases, including osteoarthritis and RA, through regulating diverse cellular processes such as cell proliferation, differentiation, signal transduction, immune response and apoptosis [40].

In our study, miR-26b elevated the expression of $\beta$ catenin and CyclinD1 by lowering GSK-3 $\beta$ expression, which in-turn activated Wnt/GSK-3 $\beta / \beta$-catenin pathway, inhibited RAFLS apoptosis and led to increased secretion of TNF- $\alpha, I L-1 \beta$ and IL- 6 . Thus, miR-26b plays a central role in pathways controlling inflammation in reumatoid arthritis. Wnt is a secreted protein important in cell proliferation, differentiation, cell morphology, cell adhesion, cell motility and development [41]. In addition, $\beta$-catenin has a dual function in regulating gene transcription and in cell-cell adhesion [42]. As a component of the cadherin protein complex, $\beta$-catenin is an intracellular signal

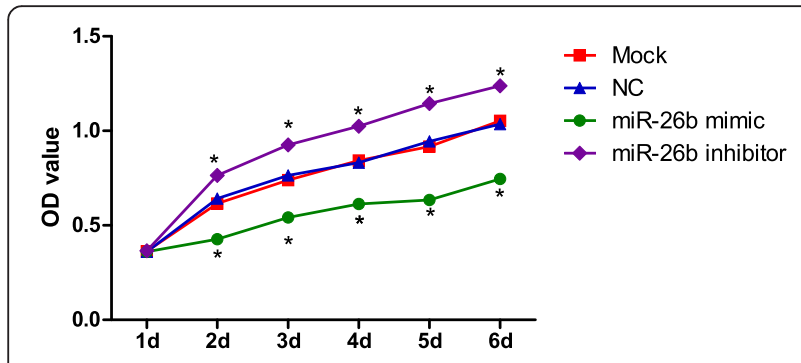

Fig. 6 The MTT assay results for cell proliferation, ${ }^{*}$, comparison between Mock group and NC group, $P<0.05$. NC, negative control transducer of cell polarity and also functions in the Wnt signaling pathway [43]. Jong Hui Suh et al. demonstrated that miR-26a, which has the same core sequence with miR-26b, is indeed a functional gene product and is capable of binding to GSK-3 $\beta$ and directly regulating its expression [44]. GSK-3 $\beta$ is a regulator of $\beta$-catenin levels and Wnt-induced intracellular signaling sequesters $\beta$ catenin from GSK-3 $\beta$ and promotes its nuclear accumulation, allowing $\beta$-catenin to complex with T-cell factor/ lymphocyte enhancer binding factor (TCF/LEF) to activate transcription of target genes [45]. GSK-3 $\beta$, functions at the upstream step of $\mathrm{Wnt} / \beta$-catenin signaling pathway and is one of the most important negative regulatory component in the cell to control $\beta$-catenin function [46]. GSK$3 \beta$ directly regulates $\beta$-catenin availability in the nucleus, depending on the intensity of the Wnt signaling pathway, by phosphorylating $\beta$-catenin in the cytosol and targeting it for ubiquitin-dependent proteolysis [47, 48]. GSK-3 $\beta$ was later found to regulate key signaling events relating to multiple aspects of cellular function, including protein synthesis, cytoskeletal integrity and gene expression [49]. In this study, transfection of miR-26b led to a significant increase in total GSK-3 $\beta$ and a decrease in the inhibitory phosphorylation on Ser9-GSK-3 $\beta$, strongly influencing Wnt/GSK-3 $\beta / \beta$-catenin pathway. Therefore, we believe that miR-26b is specific to this pathway and has a prominent role in inhibiting RA synovial inflammation. Consistent with this interpretation, Wnt- 4 and Wnt- $5 \alpha$ showed no significant differences in our study. Wnt- $5 \alpha$ alters cell morphology by reducing cell adhesion and members of this family activate the non-canonical Wnt pathway.

Our study revealed that transfection of miR-26b significantly inhibited NF- $\mathrm{B}$ activity, as judged by the sharply decreased levels of tumor necrosis factor (TNF)- $\alpha$, IL-1 $\beta$ and IL-6. Although the exact mechanism of this effect need to be further investigated, we believe that miR-26b is intimately involved in RA progression and miR-26b based strategies have the potential to be highly effective against synovium inflammation in RA, consistent with earlier observations by Turner-Brannen et al. [50]. Our study is also supported by Tomoyuki Nakasa et al., who presented convincing results that NF- $\mathrm{kB}$ activity is critical for the initiation and maintenance of chronic inflammation in RA synovial tissue [15].

It is interesting to note a significant decrease in RASF proliferation after miR-26b transfection. Compared with healthy individuals, hyperplasia of synovial cells is induced by excessive cell proliferation or/and defects in apoptosis, leading to synovial lining thickness of up to 10-15 cell layers $[51,52]$. Synovial hyperplasia can also promote the synovium attachment to the adjoining cartilage and bone, which causes joint dysfunction [53]. Clinically, arthroscopic synovectomy is very affective in patients with high synovial hyperplasia in local joints, 

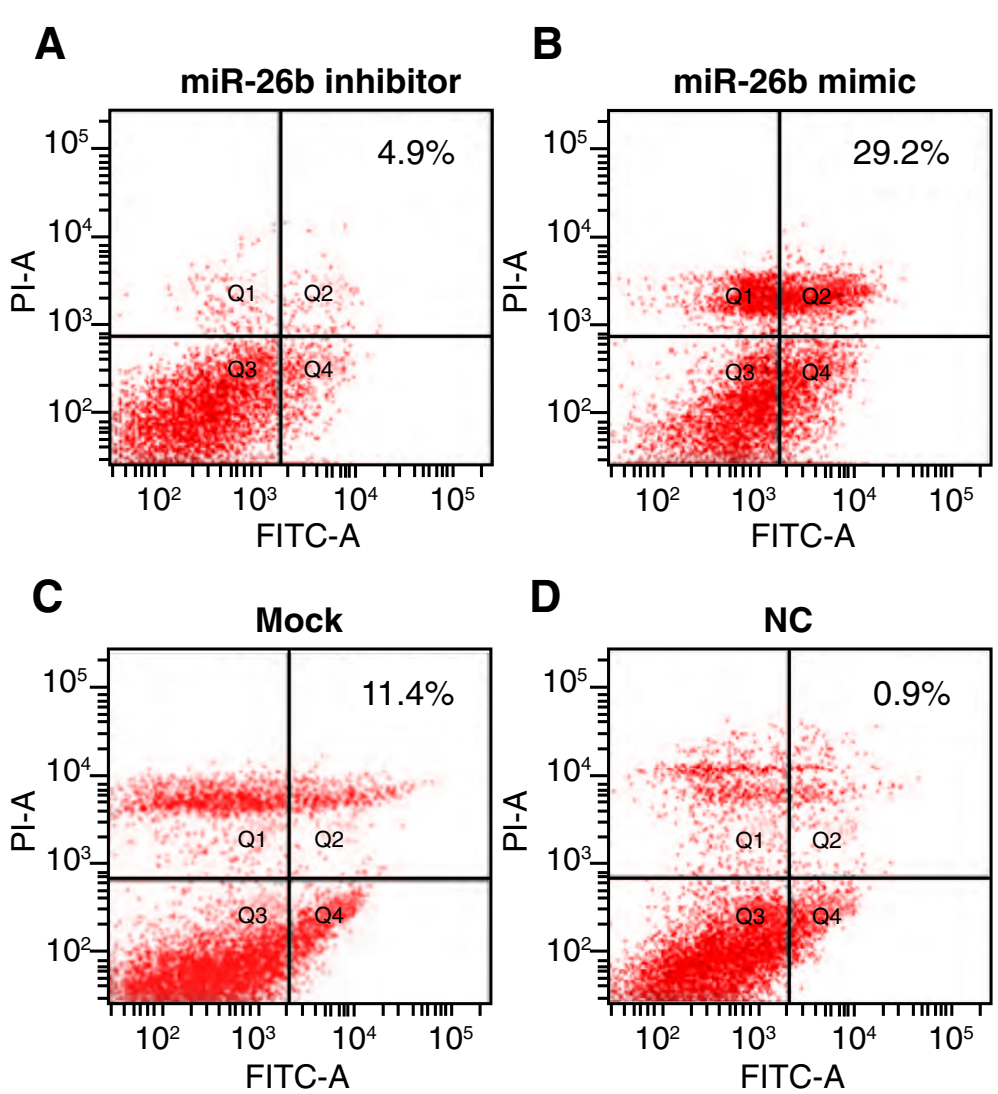

Fig. 7 Effects of miR-26b on RAFLS apoptosis (Q1:necrotic cells; Q2:apoptotic cells; Q3:living cells; Q4:early apoptotic cells. Apoptosis rate of RAFLS in miR-26b inhibitor group is lower than Mock and NC group, while the rate in miR-26b mimic group is higher than Mock and NC group; apoptosis rates between Mock and NC group showed no significant differences). NC, negative control

suggesting that hyperplasia of synovial cells plays an important role in RA pathology and joint function [54].

\section{Conclusions}

Based on our results, we propose that the proliferation of synovial fibroblast is a significant event in RA and inhibition of hyperplasia may be an effective treatment for RA. MiR-26b may be useful to down-regulate SF hyperplasia and inhibit synovium inflammation. In summary, miR-26b inhibits RASF proliferation and reduces secretion of inflammatory cytokines, including TNF- $\alpha, I L-1 \beta$ and IL-6, via inhibiting Wnt/GSK-3 $\beta / \beta$-catenin pathway through regulating GSK-3 $\beta$ level.

\section{Competing interests}

The authors declare that they have no competing interests.

\section{Authors' contribution}

G-YX participated in the study design, carried out the measurements and drafted the manuscript. H-JM participated in the study design and performed the analysis. YQ participated in the study design, drafted the manuscript and revised it critically for important intellectual content. All authors read and approved the final manuscript.

\section{Acknowledgments}

We would like to give our sincere appreciation to the reviewers for their helpful comments on this article.

\section{Author details}

${ }^{1}$ Nursing Office, Linyi People's Hospital, Linyi 276000, P. R. China.

2Department of Rheumatology, Linyi People's Hospital, Linyi 276000, P. R. China. ${ }^{3}$ Department of Burn and Plastic Surgery, Linyi People's Hospital, Linyi 276000, P. R. China. ${ }^{4}$ Department of Orthopedics, Linyi People's Hospital, North of Yimeng Road, Lanshan District, Linyi 276000, P. R. China.

${ }^{5}$ Department of Orthopaedics, Nanjing Drum Tower Hospital The Affiliated Hospital of Nanjing University Medical School, Nanjing 210008, P. R. China.

Received: 24 December 2014 Accepted: 2 June 2015

Published online: 19 June 2015

\section{References}

1. Boissier MC, Semerano L, Challal S, Saidenberg-Kermanac'h N, Falgarone G. Rheumatoid arthritis: from autoimmunity to synovitis and joint destruction. J Autoimmun. 2012;39:222-8.

2. Tobon GJ, Youinou P, Saraux A. The environment, geo-epidemiology, and autoimmune disease: Rheumatoid arthritis. J Autoimmun. 2010;35:10-4.

3. van de Sande MG, de Hair MJ, van der Leij C, Klarenbeek PL, Bos WH, Smith $M D$, et al. Different stages of rheumatoid arthritis: features of the synovium in the preclinical phase. Ann Rheum Dis. 2011;70:772-7.

4. Prete M, Racanelli V, Digiglio L, Vacca A, Dammacco F, Perosa F. Extra-articular manifestations of rheumatoid arthritis: An update. Autoimmun Rev. 2011;11:123-31.

5. Covic T, Cumming SR, Pallant JF, Manolios N, Emery P, Conaghan PG, et al. Depression and anxiety in patients with rheumatoid arthritis: prevalence 
rates based on a comparison of the Depression, Anxiety and Stress Scale (DASS) and the hospital, Anxiety and Depression Scale (HADS). BMC Psychiatry. 2012;12:6.

6. Chung CP, Giles JT, Petri M, Szklo M, Post W, Blumenthal RS, et al. Prevalence of traditional modifiable cardiovascular risk factors in patients with rheumatoid arthritis: comparison with control subjects from the multi-ethnic study of atherosclerosis. Semin Arthritis Rheum. 2012;41:535-44.

7. Snir O, Gomez-Cabrero D, Montes A, Perez-Pampin E, Gomez-Reino JJ, Seddighzadeh M, et al. Non-HLA genes PTPN22, CDK6 and PADI4 are associated with specific autoantibodies in HLA-defined subgroups of rheumatoid arthritis. Arthritis Res Ther. 2014;16:414.

8. Viatte S, Plant D, Raychaudhuri S. Genetics and epigenetics of rheumatoid arthritis. Nat Rev Rheumatol. 2013;9:141-53.

9. Scott IC, Steer S, Lewis CM, Cope AP. Precipitating and perpetuating factors of rheumatoid arthritis immunopathology: linking the triad of genetic predisposition, environmental risk factors and autoimmunity to disease pathogenesis. Best Pract Res Clin Rheumatol. 2011;25:447-68.

10. Klareskog L, Malmstrom V, Lundberg K, Padyukov L, Alfredsson L. Smoking, citrullination and genetic variability in the immunopathogenesis of rheumatoid arthritis. Semin Immunol. 2011;23:92-8.

11. Zuo W, Wu ZH, Wu N, Duan YH, Wu JT, Wang H, et al. Adiponectin receptor 1 mediates the difference in adiponectin- induced prostaglandin E2 production in rheumatoid arthritis and osteoarthritis synovial fibroblasts. Chin Med J (Engl). 2011;124:3919-24

12. Wang JF, Guan ZP, Zhang SL, Pei Z, Chen YY, Pan H. Programmed cell death 5 correlates with disease activity and interleukin-17 in serum and synovial fluid of rheumatoid arthritis patients. Chin Med J (Engl). 2013;126:296-9.

13. Gabay C, Lamacchia C, Palmer G. IL-1 pathways in inflammation and human diseases. Nat Rev Rheumatol. 2010;6:232-41.

14. Grabiec AM, Korchynskyi O, Tak PP, Reedquist KA. Histone deacetylase inhibitors suppress rheumatoid arthritis fibroblast-like synoviocyte and macrophage IL-6 production by accelerating mRNA decay. Ann Rheum Dis. 2012;71:424-31.

15. Nakasa T, Miyaki S, Okubo A, Hashimoto M, Nishida K, Ochi M, et al. Expression of microRNA-146 in rheumatoid arthritis synovial tissue. Arthritis Rheum. 2008;58:1284-92.

16. Stanczyk J, Pedrioli DM, Brentano F, Sanchez-Pernaute O, Kolling C, Gay RE, et al. Altered expression of MicroRNA in synovial fibroblasts and synovial tissue in rheumatoid arthritis. Arthritis Rheum. 2008;58:1001-9.

17. Furer V, Greenberg JD, Attur M, Abramson SB, Pillinger MH. The role of microRNA in rheumatoid arthritis and other autoimmune diseases. Clin Immunol. 2010;136:1-15.

18. Zhao N, Wang R, Zhou L, Zhu Y, Gong J, Zhuang SM. MicroRNA-26b suppresses the NF-kappaB signaling and enhances the chemosensitivity of hepatocellular carcinoma cells by targeting TAK1 and TAB3. Mol Cancer. 2014;13:35.

19. Li J, Kong X, Zhang J, Luo Q, Li X, Fang L. MiRNA-26b inhibits proliferation by targeting PTGS2 in breast cancer. Cancer Cell Int. 2013;13:7.

20. Song $G, X u G$, Ji C, Shi $C$, Shen $Y$, Chen $L$, et al. The role of microRNA-26b in human adipocyte differentiation and proliferation. Gene. 2014;533:481-7.

21. Dumortier O, Hinault C, Van Obberghen E. MicroRNAs and metabolism crosstalk in energy homeostasis. Cell Metab. 2013;18:312-24.

22. Shin D, Howng SY, Ptacek LJ, Fu YH. miR-32 and its target SLC45A3 regulate the lipid metabolism of oligodendrocytes and myelin. Neuroscience. 2012;213:29-37.

23. Png K, Yoshida M, Zhang XH, Shu W, Lee $H$, Rimner A, et al. MicroRNA-335 inhibits tumor reinitiation and is silenced through genetic and epigenetic mechanisms in human breast cancer. Genes Dev. 2011;25:226-31.

24. Lu Z, Li Y, Takwi A, Li B, Zhang J, Conklin DJ, et al. miR-301a as an NF-kappaB activator in pancreatic cancer cells. EMBO J. 2011;30:57-67.

25. Jiang $L$, Lin C, Song $L$, Wu J, Chen B, Ying Z, et al. MicroRNA-30e* promotes human glioma cell invasiveness in an orthotopic xenotransplantation model by disrupting the NF-kappaB/IkappaBalpha negative feedback loop. J Clin Invest. 2012;122:33-47.

26. Song L, Liu L, Wu Z, Li Y, Ying Z, Lin C, et al. TGF-beta induces miR-182 to sustain NF-kappaB activation in glioma subsets. J Clin Invest. 2012;122:3563-78.

27. Zhu Y, Lu Y, Zhang Q, Liu JJ, Li TJ, Yang JR, et al. MicroRNA-26a/b and their host genes cooperate to inhibit the G1/S transition by activating the pRb protein. Nucleic Acids Res. 2012:40:4615-25.

28. Ji J, Shi J, Budhu A, Yu Z, Forgues M, Roessler S, et al. MicroRNA expression, survival, and response to interferon in liver cancer. N Engl J Med. 2009;361:1437-47.
29. Zhang B, Liu XX, He JR, Zhou CX, Guo M, He M, et al. Pathologically decreased miR-26a antagonizes apoptosis and facilitates carcinogenesis by targeting MTDH and EZH2 in breast cancer. Carcinogenesis. 2011;32:2-9.

30. Lu J, He ML, Wang L, Chen Y, Liu X, Dong Q, et al. MiR-26a inhibits cell growth and tumorigenesis of nasopharyngeal carcinoma through repression of EZH2. Cancer Res. 2011;71:225-33.

31. Reuland SN, Smith SM, Bemis LT, Goldstein NB, Almeida AR, Partyka KA, et al. MicroRNA-26a is strongly downregulated in melanoma and induces cell death through repression of silencer of death domains (SODD). J Invest Dermatol. 2013;133:1286-93.

32. Arnett FC, Edworthy SM, Bloch DA, McShane DJ, Fries JF, Cooper NS, et al. The American Rheumatism Association 1987 revised criteria for the classification of rheumatoid arthritis. Arthritis Rheum. 1988;31:315-24

33. Olson AL, Swigris JJ, Sprunger DB, Fischer A, Fernandez-Perez ER, Solomon J, et al. Rheumatoid arthritis-interstitial lung disease-associated mortality. Am J Respir Crit Care Med. 2011;183:372-8.

34. Avina-Zubieta JA, Thomas J, Sadatsafavi M, Lehman AJ, Lacaille D. Risk of incident cardiovascular events in patients with rheumatoid arthritis: a meta-analysis of observational studies. Ann Rheum Dis. 2012;71:1524-9.

35. Massardo L, Pons-Estel BA, Wojdyla D, Cardiel MH, Galarza-Maldonado CM, Sacnun MP, et al. Early rheumatoid arthritis in Latin America: low socioeconomic status related to high disease activity at baseline. Arthritis Care Res (Hoboken). 2012;64:1135-43.

36. O'Connell RM, Rao DS, Baltimore D. microRNA regulation of inflammatory responses. Annu Rev Immunol. 2012;30:295-312.

37. Reid G, Kirschner MB, van Zandwijk N. Circulating microRNAs: Association with disease and potential use as biomarkers. Crit Rev Oncol Hematol. 2011;80:193-208.

38. Shin VY, Chu KM. MiRNA as potential biomarkers and therapeutic targets for gastric cancer. World J Gastroenterol. 2014;20:10432-9.

39. Bostjancic E, Jerse M, Glavac D, Zidar N: miR-1, miR-133a/b, and miR-208a in human fetal hearts correlate to the apoptotic and proliferation markers. Exp Biol Med (Maywood). 2015;240:211-9.

40. Shang J, Liu H, Zhou Y. Roles of microRNAs in prenatal chondrogenesis, postnatal chondrogenesis and cartilage-related diseases. J Cell Mol Med. 2013;17:1515-24.

41. de Lau W, Barker N, Low TY, Koo BK, Li VS, Teunissen H, et al. Lgr5 homologues associate with Wnt receptors and mediate R-spondin signalling. Nature. 2011;476:293-7.

42. Muche S, Kirschnick M, Schwarz M, Braeuning A. Synergistic effects of beta-catenin inhibitors and sorafenib in hepatoma cells. Anticancer Res. 2014;34:4677-83.

43. Cruciat CM. Casein kinase 1 and Wnt/beta-catenin signaling. Curr Opin Cell Biol. 2014;31C:46-55

44. Suh JH, Choi E, Cha MJ, Song BW, Ham O, Lee SY, et al. Up-regulation of miR-26a promotes apoptosis of hypoxic rat neonatal cardiomyocytes by repressing GSK-3beta protein expression. Biochem Biophys Res Commun. 2012:423:404-10.

45. Lin X, Faroogi AA, Ismail M. Recent progress in fungus-derived bioactive agents for targeting of signaling machinery in cancer cells. Drug Des Devel Ther. 2015;9:1797-804.

46. Arioka M, Takahashi-Yanaga F, Sasaki M, Yoshihara T, Morimoto S, Takashima A, et al. Acceleration of bone development and regeneration through the Wnt/beta-catenin signaling pathway in mice heterozygously deficient for GSK-3beta. Biochem Biophys Res Commun. 2013;440:677-82.

47. Gao Y, Liu Z, Zhang X, He J, Pan Y, Hao F, et al. Inhibition of cytoplasmic GSK-3beta increases cisplatin resistance through activation of Wnt/beta-catenin signaling in A549/DDP cells. Cancer Lett. 2013;336:231-9.

48. Go HS, Kim KC, Choi CS, Jeon SJ, Kwon KJ, Han SH, et al. Prenatal exposure to valproic acid increases the neural progenitor cell pool and induces macrocephaly in rat brain via a mechanism involving the GSK-3beta/betacatenin pathway. Neuropharmacology. 2012;63:1028-41.

49. Mohamed JS, Lopez MA, Boriek AM. Mechanical stretch up-regulates microRNA-26a and induces human airway smooth muscle hypertrophy by suppressing glycogen synthase kinase-3beta. J Biol Chem. 2010;285:29336-47

50. Turner-Brannen E, Choi KY, Arsenault R, El-Gabalawy H, Napper S, Mookherjee N. Inflammatory cytokines IL-32 and IL-17 have common signaling intermediates despite differential dependence on TNF-receptor 1. J Immunol. 2011;186:7127-35.

51. Xu Z, Wu G, Wei X, Chen X, Wang Y, Chen L. Celastrol induced DNA damage, cell cycle arrest, and apoptosis in human rheumatoid fibroblast-like synovial cells. Am J Chin Med. 2013;41:615-28. 
52. Neumann E, Lefevre S, Zimmermann B, Gay S, Muller-Ladner U. Rheumatoid arthritis progression mediated by activated synovial fibroblasts. Trends $\mathrm{Mol}$ Med. 2010;16:458-68.

53. Korb-Pap A, Stratis A, Muhlenberg K, Niederreiter B, Hayer S, Echtermeyer F, et al. Early structural changes in cartilage and bone are required for the attachment and invasion of inflamed synovial tissue during destructive inflammatory arthritis. Ann Rheum Dis. 2012;71:1004-11.

54. Choi WJ, Choi GW, Lee JW. Arthroscopic synovectomy of the ankle in rheumatoid arthritis. Arthroscopy. 2013;29:133-40.

Submit your next manuscript to BioMed Central and take full advantage of:

- Convenient online submission

- Thorough peer review

- No space constraints or color figure charges

- Immediate publication on acceptance

- Inclusion in PubMed, CAS, Scopus and Google Scholar

- Research which is freely available for redistribution 